\title{
ANALISIS PENGENDALIAN KUALITAS TERJADINYA CACAT PADA PROSES PRODUKSI ADJUSTER R KWB (Studi Kasus di PT. Dina Karya Pratama. (Cicadas-Bogor)
}

\section{Analysis of Quality Control Defects In Production Process Adjuster R KWB}

\author{
Dr. Indrani Dharmayanti ${ }^{1}$, Ajeng Rahayu ${ }^{2}$ \\ Program Studi Manajemen Produksi, Politeknik APP Jakarta ${ }^{1}$ \\ Program Studi Perdagangan Internasional, , Politeknik APP Jakarta ${ }^{2}$ \\ E-mail: lindh522@gmail.com
}

\begin{abstract}
This study aims to find out the production process of Adjuster R KWB (a part of automotive sparepart), the defect analysis and causes in PT. Dina Karya Pratama. It is a manufacturing company engaged in metal industry, especially automotive,. Quality control analysis is done using statistical called seven tools consisting of check sheet, $p$ control chart, pareto diagram, and cause and effect diagram to answer those problems. The results of analysis show that the production process is controlled by the average proportion of defects (0.0071283). The level of disability is dominated by screw jam (50\%) and circle not symmetry (35\%). The main factors causing the defect are the engine factor that has not been hot, the method factor and the inaccuracy of labor.
\end{abstract}

Keywords: Quality Control, Statistical Quality Control (SQC), Seven Tools

\begin{abstract}
Abstrak
Penelitian ini bertujuan untuk mengetahui proses produksi Adjuster $R$ KWB (sebuah komponen pada sparepart otomotif), analisis jenis kecacatan dan penyebabnya pada PT.Dina Karya Pratama, sebuah perusahaan Manufacturing yang bergerak di bidang industri metal, terutama otomotif. Analisis pengendalian kualitas dilakukan menggunakan alat bantu statistik yang biasa disebut seven tools berupa Check sheet, Peta kendali p, diagram pareto, dan diagram sebab akibat untuk kemudian dapat menjawab penyebab permasalahan. Hasil analisis penelitian menunjukkan bahwa proses produksi terkedali dengan rata-rata proporsi cacat (0,0071283). Tingkat kecacatan didominasi oleh ulir macet (50\%) dan lingkaran tidak simetri (35\%). Faktor penyebab utama terjadinya produk cacat adalah faktor mesin yang belum panas, faktor metode, serta ketidaktelitian tenaga kerja.
\end{abstract}




\section{Pendahuluan}

Perkembangan sector industri di zaman modern ini semakin meningkat dengan pesat. Hal inilah yang mendorong perusahaan untuk berlomba menghasilkan produk yang berkualitas, sehingga perusahaan mampu bertahan dalam menghadapi persaingan. Semakin tingginya kemampuan dalam memenuhi kebutuhan konsumen berarti semakin berkualitas produk tersebut. Kualitas merupakan keseluruhan ciri dan karakteristik produk atau jasa yang kemampuannya dapat memuaskan kebutuhan, baik yang dinyatakan secara tegas maupun tersamar (Irwan \& Haryono, 2015). Keadaan ini mengakibatkan peranan kualitas semakin penting. Berbagai macam metode dikembangkan untuk mewujudkan proses produksi tanpa cacat (zero defect). Selanjutnya, manajemen kualitas adalah semua aktifitas dari fungsi manajemen secara keseluruhan yang menentukan kebijaksanaan kualitas, tujuan-tujuan dan tanggung jawab, serta mengimplementasikannya melalui alat-alat perencanaan kualitas, pengendalian kualitas, jaminan kualitas dan peningkatan kualitas (Gasprez ,2007).

PT. Dina Karya Pratama adalah perusahaan manufaktur yang bergerak dibidang industri metal, terutama otomotif roda dua. Produk yang di produksi oleh PT. Dina Karya Pratama sebanyak 33 jenis onderdil, salah satumya adalah produk Adjuster R KWB.

Dalam penelitian ini dilakukan pengendalian kualitas pada produk Adjuster R KWB, yang memiliki jumlah cacat terbanyak dibandingkan produk lainnya. Tabel 1 menunjukan tingkat kecacatan produksi PT. Dina Karya Pratama. Dengan melihat data tingkat kecacatan, maka dilakukan penelitian pengendalian kualitas produk guna mengurangi kecacatan produk Adjuster R
KWB yang pada akhirnya dapat meningkatkan profit perusahaan.

Terdapat beberapa permasalahan dalam penelitian yaitu :

1. Bagaimana proses produksi produk Adjuster R KWB yang berkualitas?

2. Apa jenis kecacatan yang paling dominan dan sebab-sebabnya dalam produksi Adjuster R KWB?

Tabel 1. Laporan Produksi

PT.Dina Karya Pratama Periode Bulan April 2016 - Maret 2017

\begin{tabular}{|c|c|c|c|c|}
\hline \multirow[b]{2}{*}{ No } & \multirow[b]{2}{*}{ Nama Part } & \multicolumn{3}{|c|}{ Periode 12 Bulan } \\
\hline & & $\begin{array}{c}\text { Total } \\
\text { Produksi }\end{array}$ & Cacat & $\begin{array}{c}\text { Persen- } \\
\text { tase }\end{array}$ \\
\hline 1 & Bracket 87A & 76.778 & 23 & $0,03 \%$ \\
\hline 2 & Adjuster R KWB & 97.812 & 844 & $0,86 \%$ \\
\hline 3 & Plate Pilion Step Side & 334.000 & 100 & $0,03 \%$ \\
\hline 4 & Bracket (11056-2959) & 0 & & \\
\hline 5 & Washer Plain $6 \mathrm{MM}$ & 289.406 & 50 & $0,02 \%$ \\
\hline 6 & Washer Plain $4 \mathrm{MM}$ & 1.069 .000 & 300 & $0,03 \%$ \\
\hline 7 & Separator B & 55,822 & 30 & $0,05 \%$ \\
\hline 8 & Bracket 11056-2729 & 0 & & \\
\hline 9 & Speedometer & 106.800 & 21 & $0,02 \%$ \\
\hline 10 & $\begin{array}{l}\text { Clamper A Brake Ho } \\
\text { (KYTF) }\end{array}$ & 54.300 & 35 & $0,06 \%$ \\
\hline 11 & Nut Fendor Set & 83.800 & 66 & $0,08 \%$ \\
\hline 12 & Plate Seat Catch & 3.800 & 24 & $0,63 \%$ \\
\hline 13 & Hook Main KWB & 50.200 & 7 & \\
\hline 14 & Bracket 11056-7184 & 20.930 & & \\
\hline 15 & Washer Plain $5 \mathrm{MM}$ & 226.557 & 30 & $0,01 \%$ \\
\hline 16 & CoverComb SW & 8.100 & & \\
\hline 17 & Bracket $11056-7185$ & 21.160 & & \\
\hline 18 & $\begin{array}{l}\text { Clamper A Brake Cable } \\
\text { (KYZA) }\end{array}$ & 38.570 & 12 & $0,03 \%$ \\
\hline 19 & $\begin{array}{l}\text { Clamper B Brake Cable } \\
\text { (KYZA) }\end{array}$ & 31.308 & & \\
\hline 21 & Washer sealing $8 \mathrm{MM}$ & 31.900 & & \\
\hline 23 & Set Spring Lock & 229.026 & 50 & $0,02 \%$ \\
\hline$\sqrt{24}$ & Bolt Stopper & 1.200 & & \\
\hline 25 & Cam $B$ & 253.532 & & \\
\hline 26 & Coflar Muffler & 150.000 & & \\
\hline 27 & Waser Doin & 118.500 & & \\
\hline 28 & Hook Helmet & 8.000 & & \\
\hline 29 & Hinge Seat & 9.170 & & \\
\hline 30 & Waser FR Fender & 3.500 & & \\
\hline 31 & Bracket 89 & 31.000 & & \\
\hline 32 & Bracket 88 & 32.160 & & \\
\hline 33 & Nut Clip 5 MM & 249.200 & & \\
\hline
\end{tabular}

Sumber : data primer yang diolah, April 2016-Maret 2017

Sesuai permasalahan yang dihadapi, maka tujuan dari penelitian ini adalah :

1. Untuk mengetahui proses produksi Adjuster R KWB

2. Mengidentifikasi kecacatan paling dominan dan mengetahui sebab sebabnya pada proses produksi Adjuster R KWB, guna memberikan 
usulan tindakan perbaikan untuk mengurangi kecacatan tersebut.

\section{Metode Penelitian}

Metode pengumpulan data dilakukan dengan pengamatan lapang atau observasi, wawancara, pengambilan data sekunder, dokumentasi, dan studi pustaka. Metode analisis yang digunakan adalah Statistics Quality Control (SQC), yang dapat lebih memudahkan mengidentifikasi, menganalisis dan memecahkan berbagai permasalahan yang berkaitan dengan pekerjaan dan menerapkannya dalam kegiatan operasional perusahaan. Cara yang efektif menerapkan metode SQC yaitu dengan menggunakan 7 Tools (Handoko, 2007).

Adapun tahapan penelitian adalah sebagai berikut:

1. Pengumpulan data produksi dan data kecacatan, kemudian diolah menggunakan lembar periksa (Check Sheet) dan disajikan dalam bentuk tabel.

2. Membuat peta kendali p. Penggunaan peta kendali $\mathrm{p}$ dikarenakan pengendalian kualitas yang dilakukan bersifat atribut, data sampel pengamatan yang diperoleh tidak tetap dan produk yang mengalanii kecacatan tersebut tidak dapat diperbaiki lagi sehingga harus ditolak (reject).

3. Menentukan prioritas perbaikan dengan melihat jenis cacat yang paling dominan/terbesar menggunakan diagram pareto (Pareto Diagram).

4. Mencari faktor penyebab yang dominan dengan diagram sebab akibat (fishbone diagram)

5. Membuat rekomendasi/ usulan perbaikan kualitas.

Beberapa penelitian pengendalian kualitas telah dilakukan sebelumnya dengan menggunakan berbagai metode seperti penelitian yang dilakukan oleh Muhammad
Elmas (2017) dengan menggunakan metode (SQC), Eva Yunita (2017) menggunakan six sigma, dan Trysha (2017) yang melakukan penelitian pengendalian kualitas dengan metode Statistical Process Control.

\section{Hasil dan Pembahasan}

\subsection{Proses Produksi Adjuster R KWB}

Berdasarkan observasi dan wawancara di PT. Dina Karya Pratama, dapat dituliskan proses produksi Adjuster R KWB adalah seperti pada Gambar 1. Dari sejumlah proses tersebut perlu diawasi setiap tahapannya, terutama pada proses blanking, bending dan drilling agar tidak mengakibatkan kecacatan pada produk. Beberapa jenis kecacatan yang terjadi pada saat proses produksi Adjuster $\mathrm{R}$ KWB antara lain:

1. Press tidak rata, karena letak produk tidak persis di tengah mengakibatkan bentuk produk jadi tidak rata.

2. Lingkaran tidak simetri, akibat pengaturan mesin salah. Ini menyebabkan letak lingkaran yang tidak pas pada posisi.

3. Ulir macet, karena mesin terlalu panas nenyebabkan mesin tidak sempurna dalam mengukur ulir pada kaki produk. 
Sumber : PT. Dina Karya Pratama (2017)

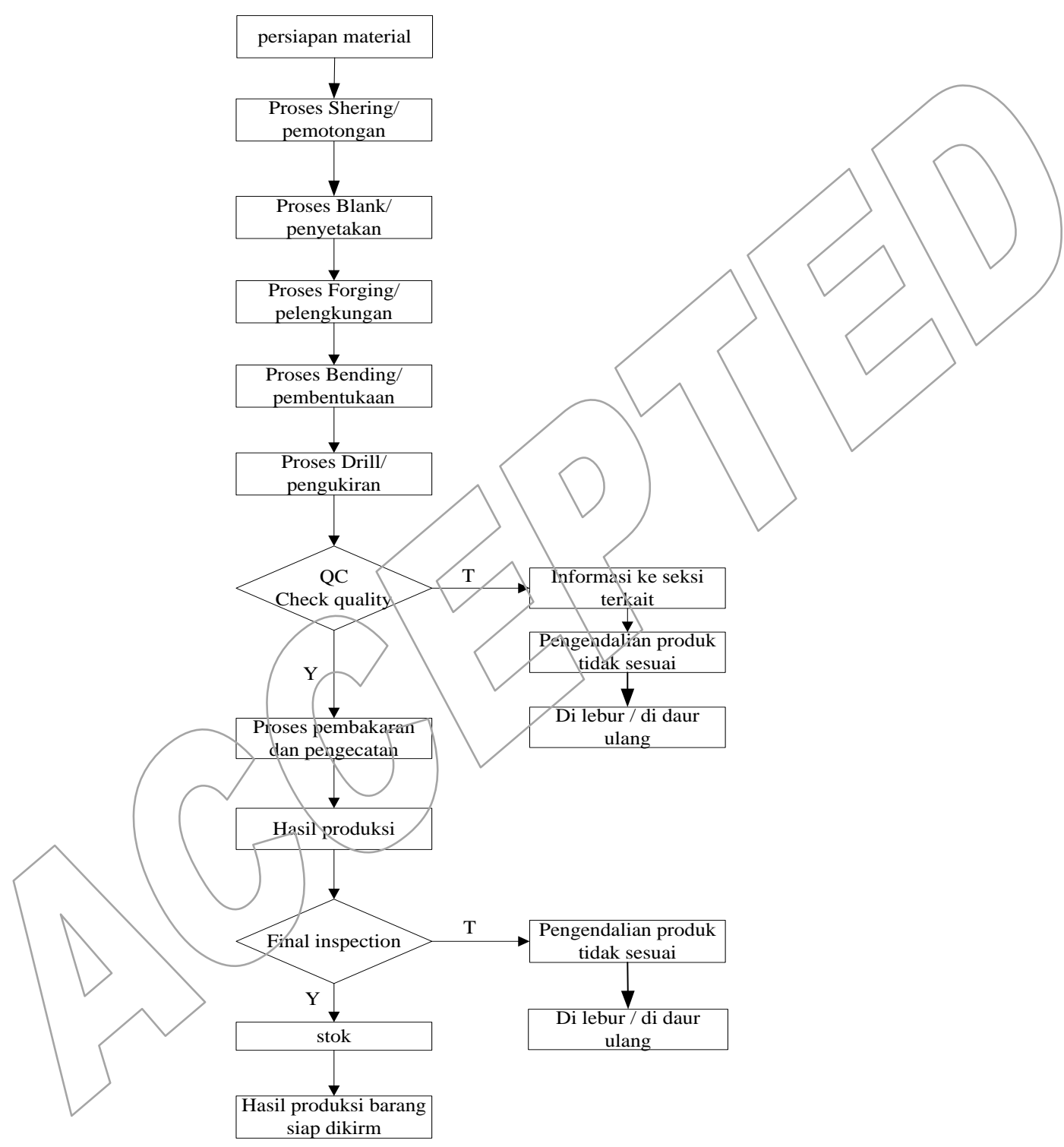

\subsection{Analisis Lembar Periksa (Check Sheet)}

Dalam melakukan pengendalian kualitas secara statistik, langkah pertama yang dilakukan adalah membuat check sheet.
Check sheet mempermudah proses pengumpulan data serta analisis, mengetahui area permasalahan berdasar frekuensi dari jenis kecacatan. Hasil pengumpulan data melalui check sheet dapat dilihat pada Tabel 2 berikut.

Tabel 2. Laporan Produksi PT. Dina Karya Pratama Periode bulan April 2016 - Maret 2017

\begin{tabular}{|c|c|c|c|c|c|c|c|c|}
\hline No & Minggn & Nama Part & Prodnksi & $\begin{array}{c}\text { Press Tidak } \\
\text { Rata }\end{array}$ & $\begin{array}{c}\text { Lingkaran } \\
\text { Tidak Simetri }\end{array}$ & $\underset{\text { Mlireet }}{\text { Ulir }}$ & $\begin{array}{c}\text { Jumlah } \\
\text { Cacat }\end{array}$ & $\begin{array}{c}\text { Presentase } \\
\text { Cacat }\end{array}$ \\
\hline 1 & $15 / 04 / 2016$ & ADUUSTER R KWB & 3.008 & 3 & 7 & 9 & 19 & $0,62 \%$ \\
\hline 2 & $22,04 / 2016$ & ADUSTER R KWB & 4.046 & 8 & 20 & 28 & 56 & $1,39 \%$ \\
\hline 3 & $29 / 04 / 2016$ & ADUSTER R KWB & 3.320 & 7 & 16 & 23 & 45 & $1,36 \%$ \\
\hline 5 & $20 \% 05 / 2016$ & ADUUSTER R KWB & $3.46 \mathrm{~s}$ & 5 & $\mathrm{~s}$ & 12 & 23 & $0,68 \%$ \\
\hline 6 & $27 / 05 / 2016$ & ADJUSTER R KWB & 2.845 & 3 & 7 & 9 & 19 & $0,66 \%$ \\
\hline 7 & $10,06 / 2016$ & ADUSTER R KWB & 3.008 & 3 & 8 & 12 & 23 & $0,77 \%$ \\
\hline 10 & $15 / 07 / 2016$ & ADUUSTER R KWB & 1.289 & 2 & 4 & 6 & 12 & $0,90 \%$ \\
\hline 11 & $22 / 07 / 2016$ & ADUUSTER R KWB & 1.734 & 5 & 12 & 18 & 35 & $2,03 \%$ \\
\hline 12 & $29 / 07 / 2016$ & ADUUSTER R KWB & 1.423 & 4 & 10 & 14 & 28 & $1,98 \%$ \\
\hline & & & & & & & & \\
\hline
\end{tabular}


Sumber : Data primer/yang diolah, April 2016 - Maret 2017

\subsection{Pembuatan Peta kendali P}

Berdasar data Tábel 2, terdapat jumlah kecacatan yang mélebihi batas toleransi cacat yang ditetapkan perusahaan yaitu sebesar $1 \%$ per produksi. Selanjutnya data dianalisis untuk mengetahui sejauh mana kecacatan yang terjadi masih dalam batas kendali statistik melalui grafik kendali.

1. perhitungan besarnya proporsi cacat untuk masing-masing pengamatan

a) Untuk pengamatan 1 pada subgroup 1

$$
\mathrm{pi}=\frac{r i}{n}=\frac{19}{3008}=0,00631552
$$

b) Untuk pengamatan 2 pada subgroup 2

$$
\mathrm{Pi}=\frac{r i}{n}=\frac{56}{4.046}=0,013841309
$$

2. Perhitungan nilai rata-rata proporsi cacat

$$
\bar{P}=\frac{\sum r \boldsymbol{r}}{\sum \boldsymbol{n}}=\frac{844}{97.812}=0,008628798
$$

3. Perhitungan batas kendali atas dan bawah (BKA dan BKB)

a) Pengamatan 1 pada subgroup 1

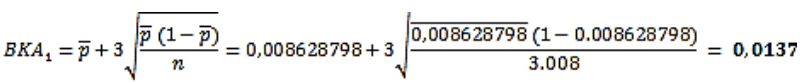

$$
\begin{aligned}
& B K B_{1}=\bar{p}-3 \sqrt{\frac{\bar{p}(1-\bar{p})}{n}}=0,008628798-3 \sqrt{\frac{0.008628798}{\frac{3.008}{1-0.008628798)}}}=0,0036
\end{aligned}
$$

b) Pengamatan 2 pada subgroup 1

\begin{tabular}{|c|c|c|c|c|c|c|c|c|c|}
\hline No & Minggu & Nama Part & Produksi & Cacat & $\begin{array}{c}\text { Proporsi } \\
\text { Cacat }\end{array}$ & $\mathrm{CL}$ & $30=3 \sqrt{\frac{\beta(1-\not)}{n}}$ & $\begin{array}{c}B K A=\bar{p} \\
+3 \sigma\end{array}$ & $\begin{array}{c}\mathrm{BKB}=\overline{\mathrm{p}}- \\
3 \sigma\end{array}$ \\
\hline 1 & $15 ; 04 / 2016$ & ADЛUSTER R KWB & 3.008 & 19 & $0,63 \%$ & 0.0086 & 0.00506 & 0.0137 & 0.0036 \\
\hline 2 & $22 ; 042016$ & ADJUSTER R KWB & 4.046 & 56 & $1,38 \%$ & 0.0086 & 0.00436 & 0.0130 & 0.0043 \\
\hline 3 & $29 ; 04 / 2016$ & ADJUSTER R KWB & 3.320 & 45 & $1,36 \%$ & 0.0086 & 0.00482 & 0.0134 & 0.0038 \\
\hline 4 & $13 ; 05 / 2016$ & ADJUTTER R KWB & 2.579 & 8 & $0,31 \%$ & 0.0086 & 0.00546 & 0.0141 & 0.0032 \\
\hline 5 & $20 ; 05 / 2016$ & ADJUTER R KWB & 3.468 & 23 & $0.66 \%$ & 0.0086 & 0.00471 & 0.0133 & 0.0039 \\
\hline 6 & $27: 05 / 2016$ & ADЛUSTER R KWB & 2.845 & 19 & $0.67 \%$ & 0.0086 & 0.00520 & 0.0138 & 0.0034 \\
\hline 7 & 10:06:2016 & ADJUSTER R KWB & 3.008 & 23 & $0.76 \%$ & 0.0086 & 0.00506 & 0.0137 & 0.0036 \\
\hline 8 & $17: 06: 2016$ & ADJUTTER R KWB & 4.046 & 71 & $1.75 \%$ & 0.0086 & 0.00436 & 0.0130 & 2.0043 \\
\hline 9 & 24:06:2016 & ADJUTTER R KWB & 3.320 & 56 & $1.69 \%$ & 0.0086 & 0.00482 & 0.0134 & 0.0038 \\
\hline 10 & $15 ; 07 / 2016$ & ADJUSTER R KWB & 1.289 & 12 & $0.93 \%$ & 0.0086 & 0.00773 & 0.0164 & 0.0009 \\
\hline
\end{tabular}

$$
\begin{aligned}
& B K A_{1}=\bar{p}+3 \sqrt{\frac{\bar{p}(1-\bar{p})}{n}}=0,008628798+3 \sqrt{\frac{0,008628798}{4.046}(1-0,008628798)}=0,0130 \\
& B K B_{1}=\bar{p}-3 \sqrt{\frac{\bar{p}(1-\bar{p})}{n}}=0,008628798-3 \sqrt{\frac{0,008628798}{4}(1-0,008628798)}=0,0043
\end{aligned}
$$

Hasil perhitungan peta kendali $p$ periode Aprill 2016 - Maret 2017 dapat dilihat pada Tabel 3.

Tabel 3. Rekapitulasi Perhitungan Batas Kendal 
4. Setelah menentukan nilai proporsi cacat (pi), rata - rata proporsi cacat ( $\mathrm{p})$, dan Batas Kendali pada Tabel 3, selanjutnya mengintegrasikan nilai $p i$ pada peta kendali, dapat dilihat pada Gambar 2.

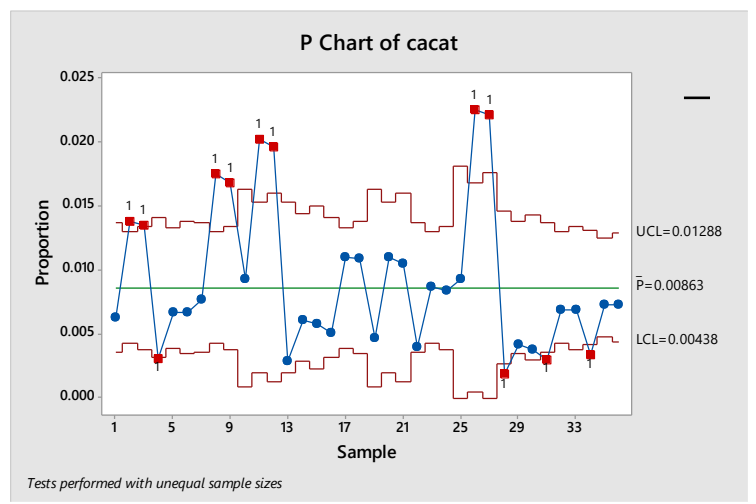

Gambar 2. Peta Kendali Proporsi Cacat pada Proses Adjuster R KWB (Sumber : Tabel 3 dengan minitab 17)

Berdasarkan grafik pada Gambar 2 dapat dilihat terdapat 12 pengamatan yang keluar dari batas kendali atas dan batas kendali bawah, sehingga bisa dikatakan bahwa proses tidak terkendali. Selanjutnya melakukan revisi peta kendali dengan menghilangkan data diluar batas kendali.

a) Penentuan besar rata - rata proporsi cacat revisi I $(\overline{\mathrm{p}})$

$\overline{\text { previsi }}_{\mathrm{I}}=\frac{\sum \mathrm{ri}-\sum \text { 'ri tidak terkendali }}{\sum \mathrm{n}-\sum \mathrm{n} \text { tidak terkendali }}=\frac{844-372}{97.812-31.597}=0,0071283$

b) Penentuan Nilai BKA dan BKB yang baru sesuai dengan rumus sebelumnya pada perhitungan peta pertama

c) Selanjutnya pengintegrasian nilai $p i$ kedalam peta kendali $p$ revisi 1 (Gambar 3) dengan menggunakan software Minitab 17 khusus untuk perhitungan Statistical Proccess Control (SPC) (Hatani, 2008).

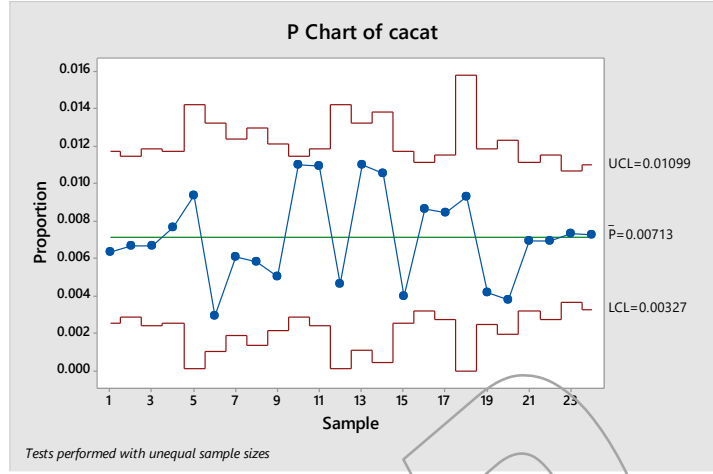

Gambar 3. Peta Kendali Proporsi Cacat Revisi I

Dari peta Kendali $\mathrm{p}$ revisi I menyatakan bahwa proses produksi terkedali secara statistik mulai dari bulan April 2016 Maret 2017 dengan rata-rata proporsi cacat produksi sebesar 0,0071283 .

\subsection{Diagram Pareto (Pareto Diagram)}

Tahap selanjutnya yaitu data pada Tabel 2 diurutkan berdasarkan jumlah cacat, mulai dari yang terbesar hingga yang terkecil dan dibuat persentase kumulatifnya. Perhitungan dilakukan untuk mengetahui persentase jenis produk yang ditolak. Dihtung menggunakan rumus sebagai berikut :

$\%$ Kerusakan $=\frac{\text { Jumlah Kerusakan Jenis }}{\text { Jumlah Kerusakan Keselurhan }} \times 100 \%$

Hasil perhitungan jumlah kecacatan pada produk Adjuster RKWB dapat dilihat pada Tabel 4.

Tabel 4. Jumlah Frekuensi cacat (berdasarkan urutan jumlahnya)

\begin{tabular}{|c|c|c|c|c|c|c|}
\hline No & Jenis Cacat & Jumlah & $\begin{array}{c}\text { Harga } \\
\text { /part }\end{array}$ & Jumlah & Persentase & $\begin{array}{l}\text { Persentase } \\
\text { Kumulatif }\end{array}$ \\
\hline 1 & Ulir macet & 422 & RP.300 & $\begin{array}{ll}\text { RP. } & 126.600 \\
\end{array}$ & $50 \%$ & $50 \%$ \\
\hline 2 & Lingkaran tidak simetri & 295 & RP.300 & $\begin{array}{ll}\text { RP. } & 88.500 \\
\end{array}$ & $35 \%$ & $85 \%$ \\
\hline 3 & Press tidak rata & 127 & RP.300 & $\begin{array}{ll}\text { RP. } & 88.100 \\
\end{array}$ & $15 \%$ & $100 \%$ \\
\hline & Total & 844 & & $\begin{array}{ll}\text { RP. } & 253.200\end{array}$ & $100 \%$ & \\
\hline
\end{tabular}


Berdasarkan data di atas maka dapat disusun sebuah diagram pareto seperti terlihat pada Gambar 4.

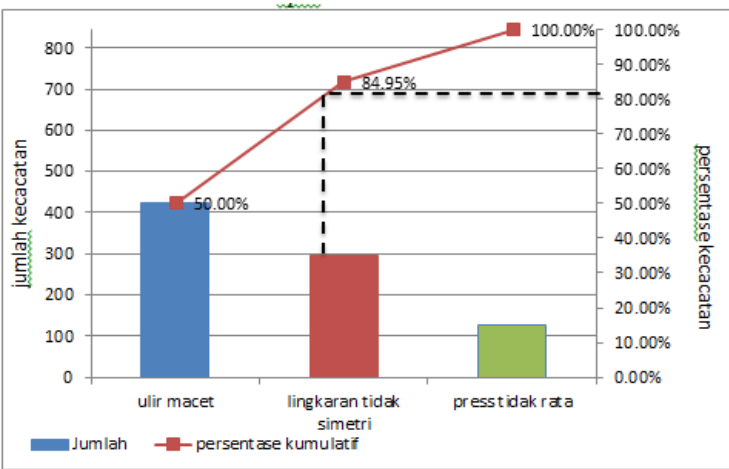

Gambar 4. Diagram Pareto tingkat kecacatan Periodebulan April 2016 - Maret 2017

Masalah yang menjadi fokus analisis peningkatan profit perusahaan adalah masalah yang mengakibatkan $80 \%$ kerusakan. Karena biaya yang dikeluarkan untuk ketiga produk reject sama yaitu sebesar Rp. 300,00/part, maka dapat dihitung jumlah kerugian yang ditanggung perusahaan akibat ulir macet sebesar Rp.126.600,00, dan akibat lingkaran tidak simetri sebesar Rp.88,500,00. Jadi fokus analisis perbaikan dilakukan pada 2 jenis kerusakan terbesar di atas.

\subsection{Diagram Sebab Akibat}

Identifikasi sebab akibat dari kecacatan di atas dapat dilihat pada Gambar 5 dan 6.

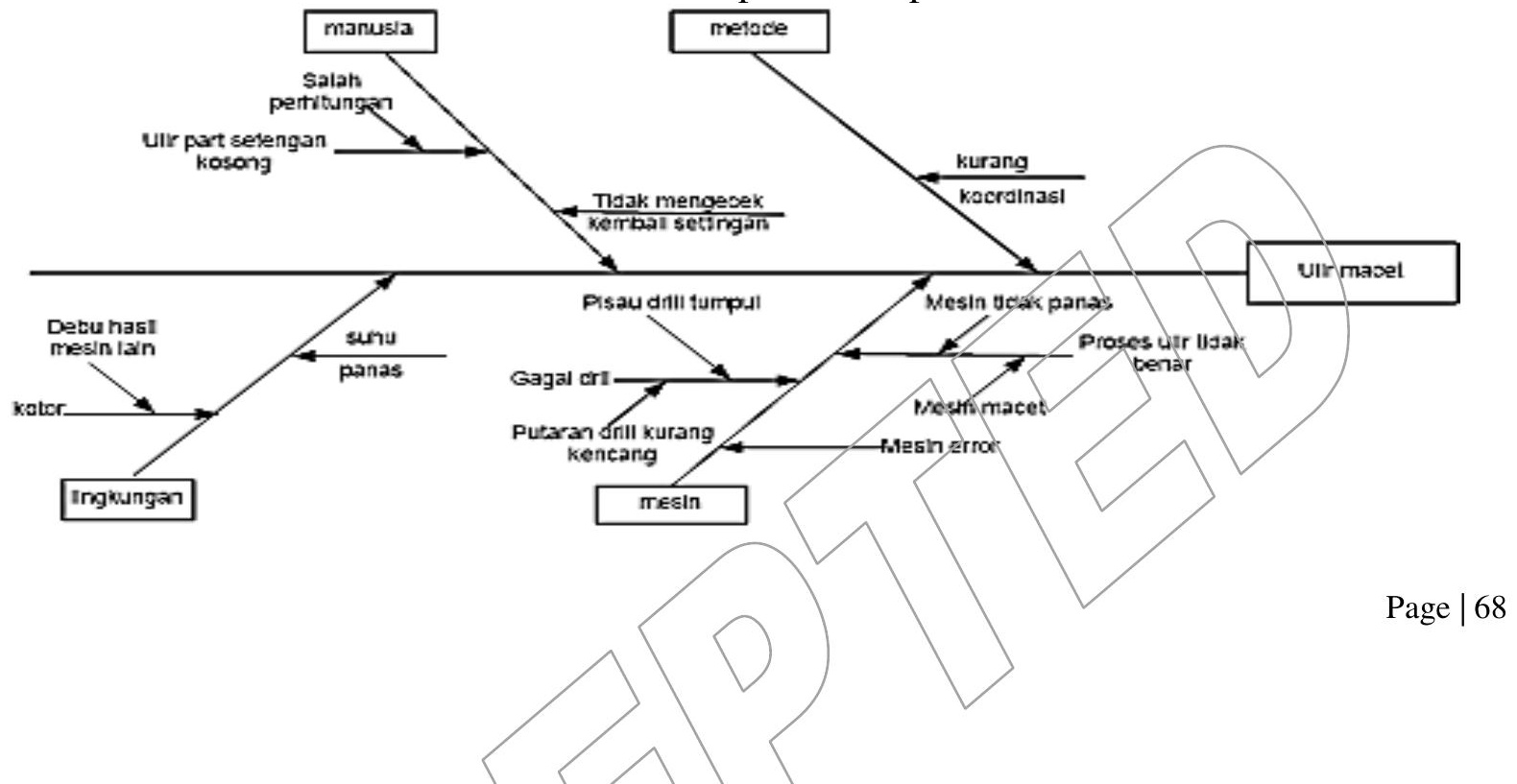

Diagram sebab akibat digunakan untuk menunjukan sebab akibat dari kecacatan.

Adapun diagram untuk masing-masing kecacatan adalah sebagai berikut :

1. Ulir macet Apabila mesin drill tidak tepat sesuai ukuran, maka akan menghasilkan produk Adjuster R KWB yang terulir setengah dan mengakibatkan ulir menjadi macet.

2. Lingkaran tidak simetri. Lingkaran part yang tidak simetri menjadikan produk Adjuster $\mathrm{R}$ KWB menjadi tidak dapat digunakan dan dapat merusak part lain jika dipasangkan. 
Gambar 5. Diagram Sebab Akibat cacat part karena ulir macet (Sumber : data primer yang di olah

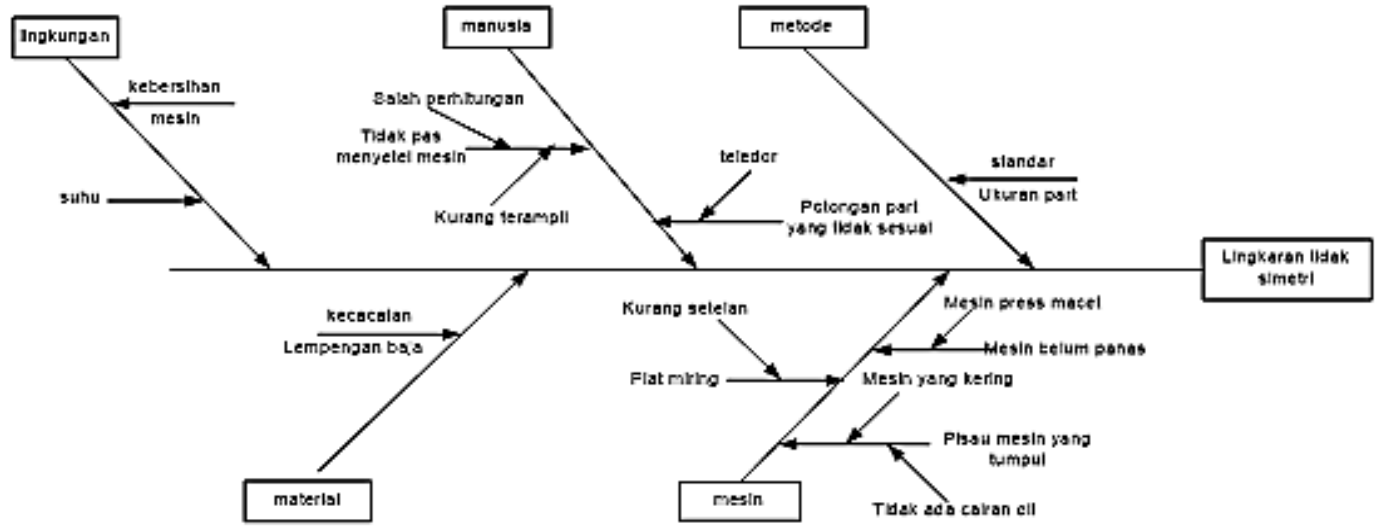

Gambar 6. Diagram Sebab Akibat cacat part karena lingkaran tidak simetri (Sumber : data primer yang di olah) 


\subsection{Usulan Tindakan Untuk Menangani Kecacatan Produk Adjuster R KWB}

Setelah mengetahui penyebab kerusakan produk Adjuster R KWB yang terjadi di PT. Dina Karya Pratama, maka disusun suatu rekomendasi atau usulan tindakan perbaikan secara umum dalam upaya menekan tingkat kerusakan produk sebagai berikut :

1. Usulan tindakan perbaikan untuk ulir macet yaitu membuat tim pengawas

yang bertugas mengawasi dan mengecek ulang kinerja operator. Bahan baku plat yang digunakan diperiksa kembali sesuai spesifikasi yang ditentukan, serta melakukan perawatan mesin secara rutin tidak hanya dilakukan ketika mesin mengalami kerusakan (preventive maintenance).

2. Usulan tindakan perbaikan untuk lingkaran tidak simetri yaitu melakukan pengecekan mesin, perawatan mesin (preventive maintenance) untuk menjaga kestabilan mesin saat berproduksi, melaksanakan briefing secara rutin setiap awal dan akhir kerja agar instruksi kerja yang diberikan bisa dilaksanakan dengan baik, menciptakan lingkungan kerja yang nyaman dan bersih agar karyawan lebih konsentrasi bekerja.

\section{Kesimpulan Dan Saran}

Berdasar hasil analisis diperoleh beberapa kesimpulan sebagai berikut :

1. Produk Adjuster R KWB diproses melalui beberapa tahap proses, yaitu shering, blank, forging, drill, dan painting.

2. Kecacatan part yang paling banyak ditemukan meliputi ulir macet $(50 \%)$, lingkaran tidak simetri (35\%) dan press tidak rata $(15 \%)$.

3. Analisis diagram sebab akibat yang fokus pada dua jenis kecacatan dominan diketahui faktor penyebab kecacatan berasal dari faktor manusia/pekerja, mesin produksi, material/bahan baku dan lingkungan kerja.

Beberapa usulan tindakan untuk menekan tingkat kerusakan produk meliputi membuat tim pengawas, melakukan pemeriksaan bahan baku plat yang digunakan, melakukan pengaturan dan perawatan mesin secara rutin (preventive maintenance). Selain itu perlu sosialisasi/ penyuluhan, khususnya mengenai SOP pada operator, melakukan recruitment SDM yang kompeten, serta adanya perbaikan lingkungan kerja seperti sirkulasi udara pada ruang produksi.

Untuk pengembangan pengetahuan dan peningkatan produktivitas perusahaan, dapat dilakukan analisis kualitas untuk produkproduk lainnya, agar dapat mengurangi kerugian perusahaan dengan menciptakan produk zero defects (kecacatan nol).

\section{Daftar Pustaka}

[1].Irwan dan Haryono. 2015. Pengendalian Kualitas Statistik. Edisi Pertama. IKAPI. Alfabeta Bandung

[2].Gasprez, Vincent. 2007. Total Quality Management. Jakarta : PT. Gramedia

[3].Handokg. Tani. 2007. Dasar-Dasar Manajemen Produksi dan Operasi. Yogyakarta : BPFE Jakarta. LPFE-UI

[4].Elmas, Muhammad Syarif Hidayatullah 2017. Pengendalian Kualitas Dengan Menggunakan Metode Statistical Quality Control untuk Meminimumkan Produk Gagal Pada Toko Roti Barokah Bakery. Diakses 24 Juli 2017. (https://www.google.com/url?sa=t\&sourc $\mathrm{e}=$ web\&rct=j\&url=https://media.neliti.co $\mathrm{m} / \mathrm{media} /$ publications/164404-IDnone.pdf\&ved=2ahUKEwiHyYnP8YzbA hUCU7wKHXEQDjgQFjAAegQICRAB \&usg=AOvVaw2M6yYgVQF52EqL7Of VIBF7)

[5]. Yunita, Eva. 2017. Analisis penen dalian Produk Dengan Metode Six Sigma Pada PT. Mahakam Media Grafik Di 
Balikpapan Diakses 24 Juli 2017. (https://www.google.com/url?sa=t\&sourc e=web\&rct=j\&url=http://ejournal.adbisnis fisip-unmul.ac.id/site/wpcontent/uploads/2017/11/jurnal\%2520eva \%2520yuvita\%2520(11-08-17-12-39-33). pdf\&ved=2ahUKEwiHyYnP8YzbAhUC U7wKHXEQDjgQFjABegQIBxAB\&usg =AOvVaw0xa0e6QWnhC8im69Q7WBv $\mathrm{m})$

[6]. Trysha, Zulfidrica. (2017), Analisis Pengendalian Kualitas Produksi Fotokopi pada CV.Surya Jaya Mandiri di Samarinda, eJournal Administrasi Bisnis, 2017, 5 (3): 690-704. Diakses 24 Juli $2017 . \quad$ https://www.google.com lurl?sa=t\&source=web\&rct=j\&url=http:// ejournal.adbisnis.fisipunmul.ac.id/site/wpcontent/uploads/2017/08/New\%2520Jurna 1\%2520Trysha\%2520(08-22-17-07-1354).doc\&ved=2ahUKEwiVrvKAozbAhULwLwKHTsMBgYQFjAAegQIA BAB\&usg=AOvVaw3zoHGfnvBMW65X iGPpJ10t

[7].Hatani, La. 2008. Manajemen Pengendalian Mutu Produksi Roti Melalui Pendekatan Statistical Quality Control (SQC), (online), (http:111 18.97.35 230/1ibrary/dinding.php? module $=$ viewdetails $\& i d=25$, diakses 24 juli 2017 , dari e-library Unhalu) 